\title{
Cortisol and behavioral responses of working dogs to environmental challenges
}

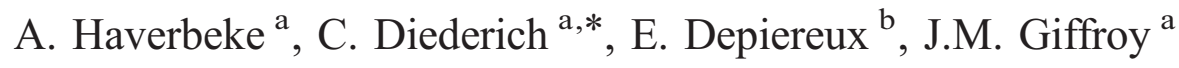 \\ ${ }^{a}$ Laboratory of Anatomy and Ethology of Domestic Animals, University of Namur (FUNDP), 6 rue Muzet, 5000 Namur, Belgium \\ ${ }^{\mathrm{b}}$ Laboratory of Biostatistics and Bioinformatics, URBM, University of Namur (FUNDP), Belgium
}

Received 10 May 2006; received in revised form 25 July 2007; accepted 26 July 2007

\begin{abstract}
This paper's primary objective is to analyse the physiological (cortisol) and behavioral responses of military working dogs (MWD). Dogs $(N=27)$ were submitted twice to environmental challenges (challenge 1 and 2, 20 days in-between) composed of social (training), visual (mobile toy car) and auditory (air blast) stimuli. Cortisol levels decreased back to the baseline after the second challenge. The behavioral observations showed that these MWD were more active, and presented less stereotypic behaviors (pacing, manipulation of the environment) during both visual challenges, whereas half low posture was observed during the first but not during the second visual challenge.

The present study shows that this group of MWD still has an adaptation capacity to an environmental challenge (return to baseline of the cortisol levels, a higher posture during the second than at the first challenge). These results are encouraging and indicate that the dogs might have a diminished welfare (i.e. stereotypic behaviors), but are not chronically stressed.
\end{abstract}

(C) 2007 Elsevier Inc. All rights reserved.

Keywords: Working dog; Cortisol; Welfare; Coping ability

\section{Introduction}

For several years, we have seen a growing interest concerning the welfare of dogs in various conditions (in kennels, at work, as companion animals) and the circumstances perturbing their welfare. Although there is no universal agreement about the definition or measurement of welfare [1-5] one of the most recognised ways to assess welfare is based on Broom's definition [6]: "welfare of an individual is its state as regards its attempts to cope with its environment at a physiological, behavioral and medical level". This approach has also been called "functioningbased" approach [7] or "homeostasis" approach [8]. Welfare could be graded into a continuum from very good to very poor.

There are different examples in the literature of studying both physiological and behavioral measurements for the assessment of chronic stress in laboratory dogs [9-14] and in shelter dogs

\footnotetext{
* Corresponding author. Tel.: +32 817405 52; fax: +32 81724420 .

E-mail addresses: anouck.haverbeke@fundp.ac.be (A. Haverbeke), claire.diederich@fundp.ac.be (C. Diederich), eric.depiereux@fundp.ac.be (E. Depiereux), jean-marie.giffroy@fundp.ac.be (J.M. Giffroy).
}

$[15,16]$. Unfortunately, few studies treat chronic welfare problems of working dogs $[17,18]$.

Cortisol is a good stress indicator for dogs $[9,15,19]$. Production of cortisol can be induced by an ACTH injection (ACTH challenge: i.e. in rodents $[20,21]$; in dogs $[9,22])$, by a challenge (i.e. sudden sound blast [9]) or by the blood sampling procedure [23-25].

Behaviors, previously associated with chronic stress, differ in dogs whether they have been challenged or not. Behaviors in challenged chronically stressed dogs (i.e. by a slamming door or by the presence of a researcher) are increased locomotor activity, circling, nosing and high levels of other behaviors (body shaking, yawning, ambivalent postures and displacement behaviors) [26]. Behaviors in unchallenged chronically stressed dogs are low posture [10], auto grooming [10,11], coprophagy [10], vocalizing [10-12], paw lifting $[10,26,27]$, high levels of locomotor activity $[11,12,26]$ or inactivity [28], nosing [26], urinating [26] and repetitive or stereotypic behaviors $[10,12,26,28,29]$.

Stereotypic behaviors, defined as acts that are invariably repeated without apparent function [30] are usually considered amongst 'the most important' indicators of long-term welfare 
problems [31]. The most frequently observed repetitive or stereotypic behaviors in kennelled dogs include manipulation of environment [10,13], circling [11,28] and pacing [11,28]. A survey of Belgian military handlers reveals the presence of stereotypic behaviors among their working dogs [32].

This paper's objective is to analyse the cortisol and behavioral responses of military working dogs (MWD) after a repeated environmental challenge to confirm whether they are chronically stressed or not.

\section{Material and methods}

\subsection{Animals}

Twenty seven dogs were selected to be a representative sample of the Military canine population as regards sex (21 males, 6 females), breed (24 Belgian shepherds, 3 German shepherds) and housing conditions (15 living in a shelter at the military kennel (MK), 12 living in a shelter at the handler's home). Two additional selection criteria were added: the animals arrived in the army at least 3 months before the study (=first selection criterion) and were operational as working dogs for a maximum of 3 years $(1.11 \pm 0.14$ years) (=second selection criterion). The first selection criterion was considered as necessary to demonstrate the adaptation of dogs in their new environment $[11,12]$. The second criterion was applied as these dogs will be compared to another group of dogs with new selection, training and evaluation program. Using these criteria, the dogs were between 1 and 5 years old ( $2.95 \pm 0.23$ years).

Because of the difficulty of documenting the source of many dogs acquired by the Belgian Defence, no attempt was made to distinguish dogs on basis of their provenance. All the dogs passed a clinical examination and were declared in good health and ready to participate to this study.

Using this sample, the effect of sex, breed and duty time have not been tested. The only factors that have been analyzed are age and housing.

Dogs were individually housed in typical indoor $(2.9 \times 1.9 \times$ $2.5 \mathrm{~m})$ - outdoor $(2.9 \times 4 \times 2.5 \mathrm{~m})$ pens. Dogs were moved to the outdoor area to record their responses to the challenges. The camera was put in front of the pen and the experimenter was out of view of the dog during filming.

\subsection{Experimental design}

This study has been carried out during a period of 29 days following an experimental design chosen in accordance with Hennessy et al. [15] and adapted to our own layout. All dogs were tested within 6 weeks, 5-6 dogs a day, and one dog at a time. On Days 8 and 29, dogs were exposed to the same challenges (respectively challenge 1 and challenge 2).

Both challenges were composed of social, visual and auditory stimuli. The social stimuli consisted in 8 obedience exercises (i.e. walk on leash, the recall) and 5 protection work exercises (i.e. handler defence and false run) accomplished outside in a maximum of $30 \mathrm{~min}$. This social stimulus, while perhaps not stressful, may at least have been rewarding and exciting. The aim of this social stimulus is to ensure that all dogs are at the same arousal level before being kennelled. It will not be included in the analysis.

After the social stimulus the dog was placed within $5 \mathrm{~min}$ in the outdoor area of a pen $(2.9 \times 4 \times 2.5 \mathrm{~m})$. After being left undisturbed for two minutes, the dog was submitted subsequently to the visual and auditory stimuli. The visual stimulus consisted in the activation by a hidden assistant of a mobile and noisy toy car in the pen during $30 \mathrm{~s}$. The toy car was already present in the pen at the entrance of the dog. This type of stimulus has been used by previous authors [33]: the toy car travelled in circles. The auditory stimulus $(110-120 \mathrm{~dB})$ was an air blast for $3 \mathrm{~s}$, at a distance of $1 \mathrm{~m}$ from the dog. This stimulus has been chosen because it represented a loud and unknown sound, was easy to use and allowed the presentation of the same stimulus to each animal. This type of stimulus has also been used by previous authors [13].

No human disturbance was allowed during testing.

\subsection{Physiological parameters}

Blood samples for assessment of plasma cortisol concentrations were collected on Days 1, 3, 8, 15, 22 and 29 between 8 and $10 \mathrm{AM}$. At Day 1, the hair over the cephalic vein of the dogs was clipped to facilitate blood sample collection. The first 3 samples (Day 1, 3, 8) were taken to identify the basal levels of cortisol. On Days 8 and 29, additional blood samples (8B, 29B) were collected between $10 \mathrm{AM}$ and $2 \mathrm{PM}$ immediately after exposure to the challenge (Day 8: challenge 1; Day 29: challenge 2).

Samples were collected within $3 \mathrm{~min}$ of the beginning of the procedure. Based on data from rodents [23-25] and from dogs [19] it is known that this is rapid enough to ensure that glucocorticoid levels are not affected by the sampling procedure. All blood samples (approximately $1 \mathrm{ml}$ ) were obtained from the cephalic vein with a needle and syringe. One individual held the $\mathrm{dog}$, and a second performed the venipuncture. The blood was rapidly transferred from the syringe to a tube containing heparin for analysis of cortisol concentration. Plasma was immediately separated in a refrigerated centrifuge during $20 \mathrm{~min}$ at $3800 \mathrm{rpm}$ and frozen at -80 degrees centigrade until analysis. Samples were assayed in duplicate with commercially available ${ }^{125} \mathrm{I}$ radioimmunoassay kits (Spectria ${ }^{\circledR}$, Orion Corporation Orion Diagnostica, Espoo, Finland).

\subsection{Behavioral observations}

During Days 1, 3, 15 and 22, after the blood sample followed by a $10 \mathrm{~min}$ walk (=exercise) with the handler, dogs were filmed in the pen where the behavior was recorded (baseline of the behaviors). The aim of this exercise is to ensure that all dogs are at the same arousal level before being kennelled. During Days 8 and 29 (challenge 1 and 2), after the first blood sampling, a 10 min walk and the social stimulus presentation, dogs were filmed in the pen where the behavior was recorded. Next, the visual stimulus was presented and behaviors were recorded while the car was moving around (=mobile car: $30 \mathrm{~s})$ and while the car was immobilized (=immobile car: $90 \mathrm{~s}$ ). During the auditory stimulus, behaviors were recorded during 
the stimulus presentation ( $3 \mathrm{~s}$ ) and after the stimulus (=air blast: $120 \mathrm{~s}$ ). The behaviors were recorded on videotape using a surveillance camera (Digital Video Camera Recorder, DCRTRV27E, Sony ${ }^{\mathbb{R}}$ ). The camera was placed in front of the cages. Behavioral observations were recorded 4 times during $12 \mathrm{~min}$ (on Days 1, 3, 15 and 22) and 2 times during 8 min (on Days 8 and 29). A total of $52 \mathrm{~min}$ were analysed for each dog for the entire study period as the first two minutes of each session were not analyzed, according to pilot taping sessions and data from other studies [34] that indicated that the dogs reacted most

Table 1

Behavioral taxonomy

The behaviors scored in terms of the frequency of occurrence
Yawning
Oral behaviors
Paw lifting
Urinating squat
Urinating limb raised
Defecating
The behaviors scored in terms of the duration of occurrence
Auto grooming
Nosing
Tail wagging:
Repetitive or stereotypic behavior
Pacing
Circling
Manipulation of environment (Man Env)

Not seen

Mouth open to apparent fullest extent while eyes are closed Includes non-directed licking (tongue out: the tip of the tongue is briefly extended), snout licking (part of the tongue is shown and moved along the upper lip), swallowing, smacking Fore paw lifted into a position of approximately $45^{\circ}$

Urinating by squatting while keeping both hind limbs on cage floor Urinating while raising one hind limb

Excreting the contents of the bowels

Behaviors directed towards the subjects own body like scratching, licking and biting Nose moved along objects and/or clear sniffing movements are exhibited Repetitive wagging movements of the tail

Immediately repeating a path just taken and continuing in the repetition; in circles, in a figure eight pattern or fence/wall-line running Continuous walking in short circles, apparently chasing its tail or hind limbs Stereotypic interactions with elements from the environment; digging (=scratching the floor with the forepaws to a way that is similar to when dogs are digging holes); floor licking (=licking the floor with the tongue); rubbing legs against bars, gnawing at bars or at other material of the environment

Unable to determine behavior of dog owing to darkness, position of dog in cage or none of these behaviors is shown

Loud, rough noise

Loud, deep sound

Low, rough sound

Long, high sound

Sudden, short, high sound

Increased frequency of inhalation and exhalation often in combination with the opening of mouth Making short loud noise by hitting teeth together

Unable to determine behavior of dog owing to darkness, position of dog in cage

Trunk of body on cage floor, chin or side of head in contact with cage side or floor, paws or limbs Trunk of body on cage floor, no part of head in contact with cage or paws

Hindquarters and front paws only in contact with cage floor

Upright with at least three paws in contact with cage floor

Takes at least one step, shifting body position

Any motion across cage floor faster than a walk, including trotting, jumping,

without coming in contact with sides of cage

Rapidly pawing bars while rearing, with one or both front paws in contact with the front of cage Rapidly pawing bars while rearing, with one or both front paws in contact with the back of cage

Rear fron

Rear back

Changing from one state of locomotion to another (Change loc)

Not seen

Unable to determine behavior of dog owing to darkness, position of dog in cage

Postures

High

Neutral

Half low

Low

Very low

Not seen
The breed specific posture as shown by dogs under neutral conditions, but in addition the tail is positioned higher or the position of the head is elevated and the ears are pointed forwards, or the animal is standing extremely erect

The breed posture shown by dogs under neutral conditions

From three features: a lowered position of the tail (compared to the neutral posture), a backward position of the ears and bent legs, two are exhibited

The position of the tail is lowered, the ears are positioned backwards and the legs are bent Low posture, but now the tail is curled forward between the hind legs Unable to determine behavior of dog owing to darkness, position of dog in cage 
intensely to the arrival of the human experimenter during the first few minutes. Videotapes were scored, using a personal computer and software designed for behavioral observation (The Observer 5.0 for Windows, Noldus Information Technology, Wageningen, The Netherlands). Intra-observer reliability exceeded $90 \%$ for all behavioral categories. Behavioral taxonomy was chosen in accordance with previous studies $[12,13]$ and adapted to our own layout (Table 1). The behaviors included within each category (stereotypic behaviors, oral miscellaneous behaviors, locomotive states and postures) were mutually exclusive. Behavior was analysed in terms of the frequency or duration of occurrence. Environmental behaviors (manipulation environment, excluding play behavior) and mobile behaviors (circling, pacing) were considered as repetitive behaviors in accordance with Beerda et al. [10] and Hubrecht et al. [28] and were analysed in terms of duration of occurrence. Moreover Beerda et al. [10] and Hubrecht et al. [28] considered these repetitive behaviors from their first moment of occurrence. However, in the present study extreme values (below the 5th and over the 95th percentile) have been classified in separated groups in order to avoid excessive influence concerning the average and the variance of the group included between these two limits. The weakest values (below the 5th percentile) have not been analysed, as they were suspected to be irrelevant; the intermediate values were considered as robust [35] and reflecting repetitive behaviors (pacing between $2.93 \mathrm{~s}-50.21 \mathrm{~s}$ of duration, circling between $0.86 \mathrm{~s}-9.62 \mathrm{~s}$, manipulation environment between $1.39 \mathrm{~s}-18.22 \mathrm{~s}$ ); the superior values (over the 95th percentile) were considered as highly repetitive behaviors (pacing of more than $50.22 \mathrm{~s}$ duration, circling more than $9.63 \mathrm{~s}$, manipulation environment more than $18.23 \mathrm{~s}$ ).

\subsection{Data analysis}

Transformation (logarithmic transformation for physiological measures; square root transformation for behavioral measures) was applied for normalization of the data and for homogenisation of the variances. Data were analysed by an analysis of variance (one way ANOVA). Pair wise comparisons between groups (Tukey's studentized range test) were conducted for those parameters that showed a significant group effect as indicated by the $F$ statistic. The level of significance was set at $p<0.05$. All the analyses were done by PROC SAS GLM [36]. For ease of presentation, all the results are expressed in raw data (mean $\pm \mathrm{SEM}$ ).

\section{Results}

The results presented are the average tendencies rather than individual differences. There were some individual differences among the dogs, but a detailed exposition of these is not within the scope of the present paper.

\subsection{Physiological analyses}

The plasma cortisol concentration was significantly higher after challenge 1 than before it (before challenge 1 (average of
Day 1, 3, 8): $39.27 \pm 4.91 \mathrm{nmol} / \mathrm{L}$, after challenge 1 (Day 8B): $64.23 \pm 6.19 \mathrm{nmol} / \mathrm{L})(F(7,204)=3.30, p<0.05)$ (Fig. 1). However that was not the case after challenge 2 (before (Day 29): $43.16 \pm 7.51 \mathrm{nmol} / \mathrm{L}$, after (Day 29B): $52.39 \pm 3.99 \mathrm{nmol} / \mathrm{L}$ ). The plasma cortisol concentrations on Day 22 and Day 29 were significantly lower than concentration on Day $8 \mathrm{~B}(F(7,204)=$ $5.13, p<0.001)$.

\subsection{Behavioral analyses}

\subsubsection{Control period}

No effects of Days 1, 3, 15 and 22 have been found on the behaviors. Therefore the average of the behaviors observed on these days was calculated and considered as the control period to be compared to the responses to the challenges (challenge 1, challenge 2) (Table 2). In the control period, the most frequently observed behaviors were pacing (repetitive behavior, $31.82 \% \pm$ 2.04 of the time observed with $28.58 \%$ highly repetitive pacing), panting (miscellaneous oral behavior, $33.74 \% \pm 3.36$ ) and the standing position (locomotion, $37.03 \% \pm 2.05$ ). Dogs spent $46 \%$ of the observed time in active gaits (walk, high active, rear front, rear back) and showed principally a high posture $(47.71 \% \pm 3.38)$.

\subsubsection{Effect of challenges on behaviors}

Regarding repetitive behaviors, there was significantly less pacing during the visual stimulus presentation (mobile car in challenge 1 and challenge 2 ) than during the control period ( $F$ $(9,259)=4.32, p<0.001)$, but there was no significant difference of pacing in presence of the mobile car between challenge 1 and challenge 2. The challenges had no influence on circling. Whatever the challenge ( 1 or 2$)$, there was less manipulation of the environment than during the control period $(F(9,259)=$ $29.31, p<0.001)$. Interestingly, the highly repetitive pacing, observed during the control period, decreased into repetitive pacing during challenge 1 (visual and auditory stimuli) and challenge 2 (visual stimulus: mobile car); at the end of challenge 2 (visual (immobile car) and auditory stimuli) pacing started to be highly repetitive again. This evolution was observed neither for circling, nor for manipulation of the environment (Table 3).

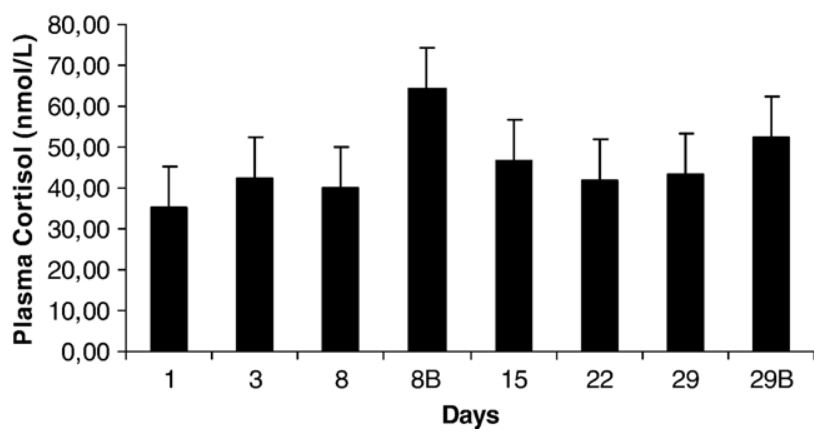

Fig. 1. Mean plasma cortisol levels of dogs sampled at Days 1, 3, 8 and 8B (=after challenge 1), 15, 22, 29 and 29B (=after challenge 2). Vertical lines represent standard errors of the means. The plasma cortisol concentration was significantly higher after challenge 1 than before it (average of Days $1,3,8$ ) $(p<0.05)$. 
Table 2

Behaviors of the dogs during the control period $\left(^{\circ}\right)$ and the challenges (challenge 1 and 2 )

\begin{tabular}{|c|c|c|c|c|c|c|c|}
\hline & \multirow[t]{2}{*}{ Control period } & \multicolumn{3}{|l|}{ Challenge 1} & \multicolumn{3}{|l|}{ Challenge 2} \\
\hline & & $\begin{array}{l}\text { Visual stimulus } \\
\text { (mobile car) }\end{array}$ & $\begin{array}{l}\text { Visual stimulus } \\
\text { (immobile car) }\end{array}$ & $\begin{array}{l}\text { Auditory stimulus } \\
\text { (air blast) }\end{array}$ & $\begin{array}{l}\text { Visual stimulus } \\
\text { (mobile car) }\end{array}$ & $\begin{array}{l}\text { Visual stimulus } \\
\text { (immobile car) }\end{array}$ & $\begin{array}{l}\text { Auditory stimulus } \\
\text { (air blast) }\end{array}$ \\
\hline \multicolumn{8}{|c|}{ Repetitive behavior } \\
\hline Pacing & $31.82 \pm 2.04$ & $7.47 \pm 2.88$ & $15.09 \pm 2.02$ & $20.64 \pm 2.45$ & $14.13 \pm 4.78$ & $25.22 \pm 5.08$ & $28.06 \pm 6.21$ \\
\hline Circling & $1.71 \pm 0.45$ & $1.64 \pm 0.38$ & $4.6 \pm 2.67$ & $1.94 \pm 1.01$ & $1.95 \pm 1.05$ & $2.53 \pm 0.86$ & $0.7 \pm 0.14$ \\
\hline Man Env & $1.02 \pm 0.3$ & 0.0 & 0.0 & $0.05 \pm 0.05$ & 0.0 & $0.2 \pm 0.2$ & $0.33 \pm 0.30$ \\
\hline \multicolumn{8}{|c|}{ Miscellaneous oral behaviors } \\
\hline Panting & $33.74 \pm 3.36$ & $45.21 \pm 7.16$ & $41.53 \pm 6.42$ & $38.20 \pm 7.29$ & $43.88 \pm 7.09$ & $44.08 \pm 7.11$ & $41.17 \pm 7.08$ \\
\hline \multicolumn{8}{|l|}{ Locomotion } \\
\hline Stand & $37.03 \pm 2.05$ & $17.36 \pm 4.67$ & $41.81 \pm 5.25$ & $42.51 \pm 5.12$ & $22.60 \pm 6.03$ & $40.35 \pm 5.28$ & $47.97 \pm 5.29$ \\
\hline Walk & $24.48 \pm 1.77$ & $15.90 \pm 5.81$ & $13.53 \pm 3.45$ & $8.63 \pm 2.42$ & $6.05 \pm 2.38$ & $13.46 \pm 3.07$ & $10.03 \pm 4.43$ \\
\hline High active & $18.29 \pm 2.72$ & $50.47 \pm 6.01$ & $30.90 \pm 5.98$ & $32.23 \pm 6.07$ & $53.99 \pm 6.66$ & $35.16 \pm 6.34$ & $31.11 \pm 5.79$ \\
\hline Rear front & $3.24 \pm 0.64$ & $1.65 \pm 1.27$ & $2.87 \pm 1.31$ & $4.04 \pm 1.69$ & $3.13 \pm 2.33$ & $3.17 \pm 2.00$ & $2.77 \pm 1.64$ \\
\hline Rear back & $0.36 \pm 0.12$ & 0.0 & $0.17 \pm 0.17$ & $0.16 \pm 0.16$ & $0.36 \pm 0.28$ & $0.77 \pm 0.56$ & $0.07 \pm 0.05$ \\
\hline \multicolumn{8}{|l|}{ Posture } \\
\hline High & $47.71 \pm 3.38$ & $49.01 \pm 8.55$ & $41.73 \pm 8.53$ & $55.19 \pm 8.50$ & $65.83 \pm 7.38$ & $67.24 \pm 7.37$ & $56.62 \pm 8.36$ \\
\hline Half low & $0.96 \pm 0.45$ & $22.21 \pm 6.63$ & $4.48 \pm 3.53$ & $5.08 \pm 3.62$ & $7.58 \pm 3.64$ & $7.46 \pm 4.74$ & $6.30 \pm 4.30$ \\
\hline
\end{tabular}

Time $\%$, means \pm SE.

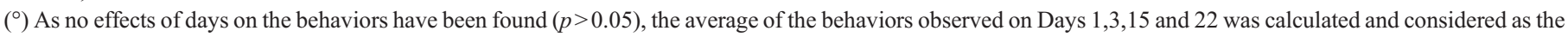
'control period'.

During the two visual stimulus presentations (mobile car in challenge 1 and challenge 2$)$, dogs were more active $(F(9,259)=$ $5.13, p<0.001)$ and stood less $(F(9,259)=6.20, p<0.001)$ than during the control period. There was more half low posture during challenge 1 (visual stimulus: mobile car) than during the control period $(F(9,259)=4.34, p<0.01)$, but not during challenge 2. During the two challenges there was less tail wagging than during the control period $(F(9,259)=6.30$, $p<0.001)$. There was no evidence of an increase in the number of yawning, oral behaviors (especially non-directed licking), paw lifting, urinating or defecating during the two challenges.

\subsection{Effect of age and housing conditions on behaviors}

The effects of age and housing conditions were subsequently examined.

In the control period and during the two challenges, 1 year old dogs spent more time pacing $(F(4,264)=9.21, p<0.001)$

Table 3

Repetitive behaviors of the dogs during the control period $\left({ }^{\circ}\right)$ and the challenges (challenge 1 and 2)

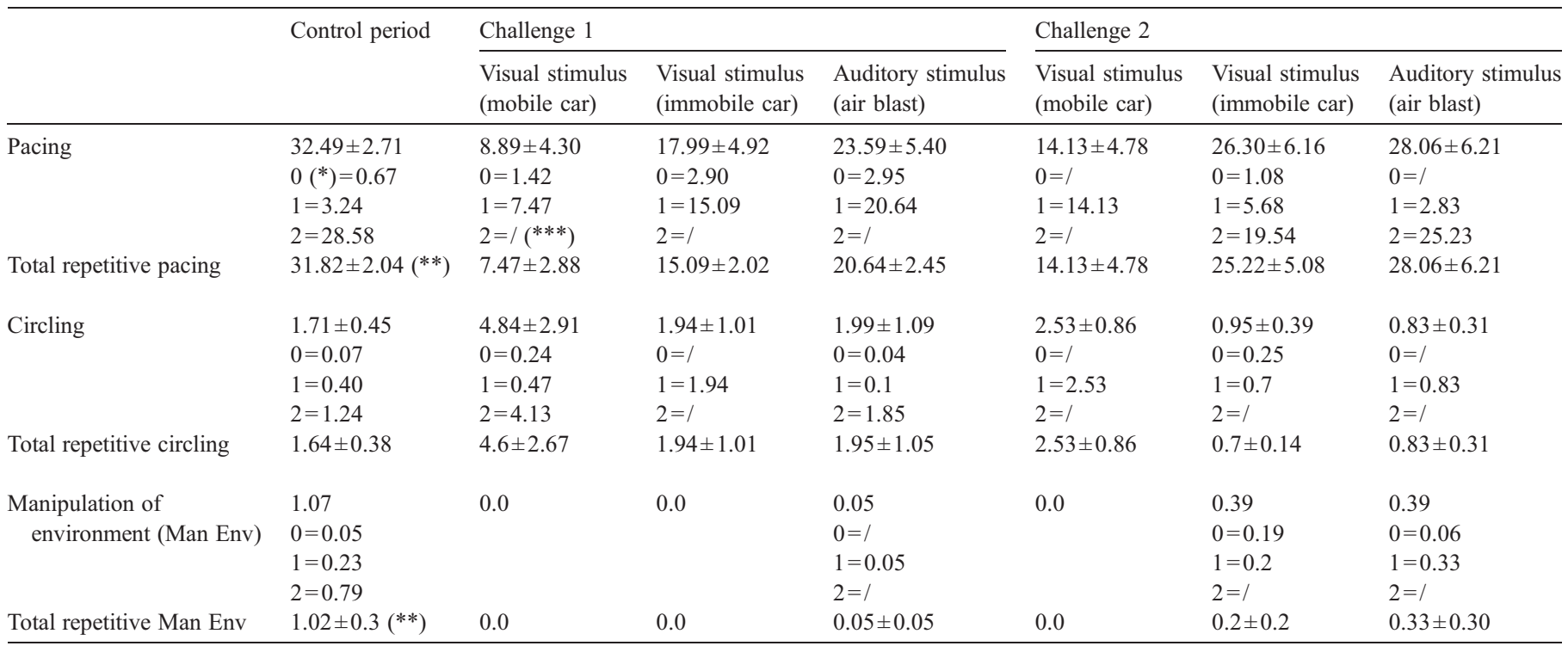

Time $\%$, means \pm SE.

$\left.{ }^{\circ}\right)$ As no effects of days on the behaviors have been found $(p>0.05)$, the average of the behaviors observed on Days $1,3,15$ and 22 was calculated and considered as the 'Control Period'.

(*) 0: not included as repetitive behaviors; 1: repetitive behaviors, 2: highly repetitive behaviors (see text for description of the 3 categories).

(**) One-way Anova, $p<0.001$

$(* * *)$ : no behavior has been found into this category. 


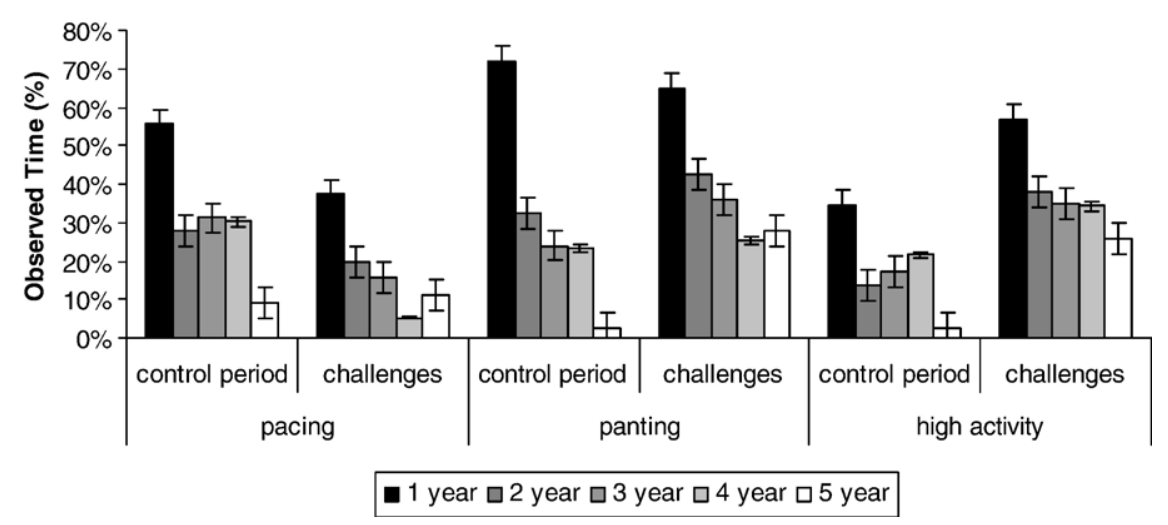

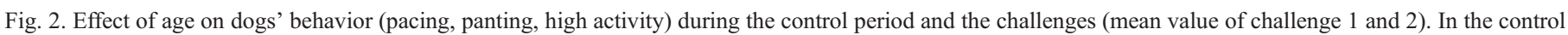
period and during the challenges, 1 year old dog (black bar) spent more time pacing and panting than older dogs (the four remaining bars) $(p<0.001)$.

and panting $(F(4,264)=11.00, p<0.001)$ than older dogs (Fig. 2).

During the challenges, dogs housed at the handlers home were less active $(F(1,158)=11.62, p<0.001)$ and exhibited more half low posture $(F(1,158)=14.97, p<0.001)$ than dogs housed at MK. Independent of the challenges, dogs housed at the handlers home showed less pacing $(F(1,107)=8.04$, $p<0.01)$, barked more $(F(1,107)=25.50, p<0.001)$, sat more $(F(1,107)=5.36, p<0.05)$ than dogs housed at the MK. During the challenges, in contrast to the control period $(F(1,62)=9.25$, $p<0.01$ ), manipulation of the environment was not influenced by housing conditions.

\section{Discussion}

The environmental challenges have been defined as acute stressors by previous authors $[13,33]$. It is interesting though to ask whether these challenges were really stressful to the dogs in the present study. Dogs might have found these challenges rather interesting and exciting compared to the barren kennel environment. The behavioral changes could all be a result of the dogs being positively stimulated or aroused rather than stressed. Henry and Stephens [37] suggest that there is only stress when there is loss of control and a reduced predictability of what will happen. So far as there is any action to obtain control with a high probability of success, there is arousal (=excitement), but no stress. In the present study, the stimuli presentations were not predictable and the interval between the challenges was long enough to prevent memorization.

\subsection{Physiological responses}

The importance of a challenge in the assessment of welfare has been shown in dogs. Beerda et al. [8,9] considered two groups of dogs outdoor housed under good and bad weather conditions. After having been housed as a group, dogs were individually indoor housed for 6 weeks in a novel environment. At the sixth week, a challenge was presented to determine in which group the dogs' welfare was most impoverished. When challenged, the bad weather group exhibited less behavioral and physiological responses than the good weather group. The welfare of the good weather group was considered as being more impoverished expressed by physiological (HPA hyporesponsiveness to acute stimuli) and behavioral signs (increased autogrooming, paw lifting, vocalizing, low posture, repetitive behavior, coprophagy).

Hennessy et al. [15] reported that the increase in cortisol plasma concentration in response to novel situations was almost twice as great during the second as during the first stressful battery if chronically stressed dogs had not received the program of human interaction during the intervening period and not significant if dogs had received the program of human interaction.

In the present study, the basal cortisol level was the average of the 3 first blood samples $(39.27 \mathrm{nmol} / \mathrm{L})$. We did not expect the heightened cortisol levels to reflect only a shift in Circadian rhythms of HPA activity because of the similar levels of basal cortisol concentrations found during the first 3 samples. Moreover, no Circadian rhythms have been established neither in laboratory dogs at $30 \mathrm{~min}$ intervals over a period of $28 \mathrm{~h} \mathrm{[38]}$ nor at $20 \mathrm{~min}$ intervals over a period of $25 \mathrm{~h} \mathrm{[39]} \mathrm{nor} \mathrm{in} \mathrm{working}$ dogs exposed to defence training and trailing tasks at $90-$

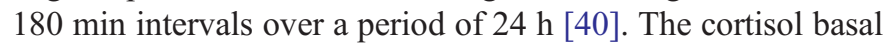
values in the present study do not show any significant differences from those of a similar group of military dogs undergoing an irregular environmental enrichment regimen (social+exercise) [18].

The basal cortisol level $(39.27 \mathrm{nmol} / \mathrm{L})$ remained within the normal range compared to other studies in dogs (approximately $25-55 \mathrm{nmol} / \mathrm{L}[15,37,41-43]$.

In this study, the first exposure to a challenge increased plasma cortisol level significantly. This is consistent with previous findings in dogs $[9,15]$ and also in rodents $[44,45]$. After 3 weeks (Day 29), the second exposure to the same challenge no longer resulted in increased plasma cortisol levels. Between the challenges, there is complete recovery from the challenges in hormonal levels. Thus, dogs are able to cope with these challenges.

\subsection{Behavioral responses}

In the present study single-housed working dogs spent $46 \%$ of the observed time of the control period in active gaits (walk, 
high active, rear front, rear back). It was higher than previous data in working dogs $(5 \%$ to $30 \%$ : $[18,46])$ or in laboratory dogs (5\% to $15 \%$ : [11,28]). Dogs might have been aroused by the exercise (10 min walk) before being kennelled for videotaping.

According to Beerda et al. [10,13,26], active coping (e.g. restlessness: high levels of walking, nosing and changing from one state of locomotion to another...) has been observed in dogs during and after challenges. In the present study, an increase of activity has been found only during (mobile car) but not after (immobile car) the visual stimulus presentations (challenge 1 and 2). This restlessness cannot be attributed to previously defined situations in which restlessness has been observed: anticipating stimuli or the presence of humans [13], undergoing harsh training methods [27] or anticipating signalled shock avoidance trials [47]. But the restlessness could be due to the stimulus (mobile car) itself: when the stimulus moves, the dog moves and vice-versa.

Most studies emphasize that sound blasts are particularly stressful to dogs, since these stimuli are associated with a very low posture and elevated cortisol (for a review see [13]).

In the present study, no increase of activity was found during the auditory stimulus presentations. A possible explanation is that, due to their patrol work, these working dogs might often be exposed to and thus habituated to this kind of auditory stimulus.

The increase of activity during visual stimulus presentations (challenge 1 and challenge 2) was not accompanied by an increase in repetitive behaviors, as reported in previous studies [12,48]. Indeed, pacing and manipulation of environment decreased during visual stimulus presentations (challenge 1 and challenge 2). No influence on circling was found during the challenges, which is in disagreement with other authors [26], who reported an increase in circling among chronically stressed dogs during mild stimulation. But these authors [26] used different stimuli (slamming door or in the presence of a researcher) than in the present study (mobile car, sound blast). However at the end of the challenge 2 (auditory stimulus), pacing increased again and acquired the same level as during the control period. So it seems that in the present study, repetitive behaviors (namely pacing) were observed during the control period, but decreased during the challenges and came back again at the moment dogs did not feel stressed anymore (end of challenge 2). But further investigation must still be done, as this evolution was not observed for the other repetitive behaviors (circling, manipulation of environment).

One might interpret the decrease of pacing as orienting or alerting behavior that could be expected during presentation of a novel item in their otherwise barren environment. Authors cannot confirm this hypothesis, as no decrease of circling has been observed simultaneously.

While the results confirm the presence of stereotypic behaviors among MWD, their welfare is affected in a limited way. These dogs are still adapting to environmental challenges. Lefebvre et al.'s hypothesis [32], suggesting that this military working dog population suffers from an impoverished welfare, cannot be confirmed. It is true that stereotypies should always be taken seriously as a warning sign of potential suffering, but they cannot be used as the sole index of welfare [49]. Moreover, previous authors suggested that they correlate badly with other welfare parameters $[50,51]$.
In fact, these stereotypes could be interpreted as a behavioral scar that persists long after removal from the impoverished environment. They can be considered as products of past stress, but no longer reflecting poor welfare [52]. So, it could be that these MWD have been roughly handled in the past [32]. It could also be that they have been housed in an impoverished environment or that they have been confronted with aversive stimuli.

Earlier studies on stressed dogs have reported on increased "stress-related behaviors": vocalizing, panting, paw lifting, trembling [27,47,53,54]. In accordance with Beerda et al. [13], we found no significant increase of these behaviors after challenging working dogs. There was no evidence of an increase of the number of oral behaviors (and especially non-directed licking) during challenges. Oral behaviors are typically performed in a social context. For example, snout licking or non-directed licking, may express submission in a stressful social environment [27] and can be considered as a common sign of uneasiness or anxiety in dogs [54]. It is then not surprising that our dogs showed low levels of oral behaviors during the challenges, as no stimuli involved the presence of the experimenter.

In the present work, panting was not due to high temperature.

Yawning has been associated with psychological tension or mild stress in primates [55] and in dogs [13,15,26,56] or with possible displacement behavior indicative of conflict in dogs [57]. In the present study there was no indication of increased yawning during the challenges. A lower posture has been associated with stress [58]. The present study only confirms this statement during the first visual stimulus presentation (challenge 1), though not during the second (challenge 2).

\subsection{Effects of age and housing conditions on physiological and behavioral responses}

Younger dogs present higher activity, more pacing and panting. Though, this behavioral observation has been confirmed by previous authors [59-62], others have failed to show any effect of age on dogs' behavior activity [63].

The results of the present study do not confirm whether dogs taken home or those living at the MK present signs of decreased welfare. Wells et al. [63] for instance, found that the activity level of shelter dogs was not correlated with the age but with the time spent at the shelter.

Indeed, no physiological differences were found between the groups of dogs. Although not supported by physiological data, dogs housed at the handler's home seemed to cope less well with their environment than dogs housed at the MK. These dogs more frequently presented a half low posture and barked more than dogs housed at the MK. The reason why the coping abilities of dogs housed at MK are better, might lie in the fact that these dogs were more familiar with the environment where the study was carried out, even if home-housed dogs were accustomed to MK.

\section{Conclusion}

The present study shows that this group of MWD has a good adaptation capacity to an additional challenge (return to the baseline of the cortisol levels, a higher posture at the second 
than at the first challenge). These results are encouraging and indicate that the dogs might have a less diminished welfare (i.e. stereotypic behaviors) than supposed. Contrary to the original hypothesis and to Lefebvre et al. [32], MWD are still able to adapt to environmental challenges.

\section{Acknowledgments}

This study was supported by the University of Namur (FUNDP) and the Belgian Defence (research programme no. 2001_70-1233-51-20, A. Haverbeke).

The authors would like to thank all the Veterinary Service of the Belgian Defence and especially Vet LtCol Miguel Stevens and Vet Cdt Jan de Roo for their support and their help. The authors would also like to thank John Burns for proof reading the manuscript, the Laboratory of Physiology (J.L. Bister, FUNDP) for the cortisol analyses and the handlers for their participation in this research.

\section{References}

[1] Fraser D. Science, value and animal welfare: exploring the "inextricable connexion". Anim Welf 1995;4:103-17.

[2] Tannenbaum J. Ethics and animal welfare: the inextricable connexion. J Am Vet Med Assoc 1991;198:1360-76.

[3] Webster J. Animal welfare; a cool eye towards Eden. Second ed. Oxford: Blackwell Science; 1994. p. 10-1.

[4] Dawkins MS. From an animal's point of view: motivation, fitness and animal welfare. Behav Brain Sci 1990;13:1-61.

[5] Duncan IJH, Petherick JC. Cognition: the implications for animal welfare. Appl Anim Behav Sci 1989;24:81.

[6] Broom DM. Indicators of poor welfare. Br Vet J 1986;142:524-6.

[7] Duncan IJH, Fraser D. Understanding animal welfare. In: Appleby MC, Hughes BO, editors. Animal welfare. Oxon: CAB International; 1997. p. 19-31.

[8] Barnett JL, Hemsworth PH, Cronin GM, Jongman EC, Hutson GD. A review of the welfare issues for sows and piglets in relation to housing. Aust J Agric Resour 2001;52:1-28.

[9] Beerda B, Schilder MBH, Bernadina W, Van Hooff JARAM, De Vries HW, Mol JA. Chronic stress in dogs subjected to social and spatial restriction. II. Hormonal and immunological responses. Physiol Behav 1999;66(2):243-54.

[10] Beerda B, Schilder MBH, Van Hooff JARAM, DeVries HW, Mol JA. Chronic stress in dogs subjected to social and spatial restriction. I. Behavioral responses. Physiol Behav 1999;66(2):233-42.

[11] Hetts S, Clark JD, Calpin JP, Arnold CE, Mateo JM. Influence of housing conditions on beagle behaviour. Appl Anim Behav Sci 1992;34:137-55.

[12] Clark D, Rager DR, Crowell-Davis S, Evans DL. Housing and exercise of dogs: effects on behavior, immune function, and cortisol concentration. Lab Anim Sci 1997;47(5):500-10.

[13] Beerda B, Schilder MBH, van Hooff JARAM, de Vries HW, Mol JA. Behavioural, saliva cortisol and heart rate responses to different types of stimuli in dogs. Appl Anim Behav Sci 1998;58:365-81.

[14] Spangenberg EMF, Björklund L, Dahlborn K. Outdoor housing of laboratory dogs: effects on activity, behaviour and physiology. Appl Anim Behav Sci 2006;98(3-4):260-76.

[15] Hennessy MB, Voith VL, Hawke JL, Young TL, Centrone J, McDowell $\mathrm{AL}$, et al. Effects of a program of human interaction and alterations in diet composition on activity of the hypothalamic-pituitary-adrenal axis in dogs housed in a public animal shelter. J Am Vet Med Assoc 2002;221(1):65-71.

[16] Tuber DS, Hennessy MB, Sanders S, Miller JA. Behavioral and glucocorticoid responses of adult domestic dogs (Canis familiaris) to companionship and social separation. J Comp Physiol Psychol 1996;110(1):103-8.
[17] Burghardt WF. Behavioral considerations in the management of working dogs. Vet Clin Small Anim 2003;33:417-46.

[18] Lefebvre D, Diederich C, Giffroy JM. Cortisol and behavioural responses to enrichment in military working dogs. J Ethol, in press.

[19] Hennessy MB, Davis HN, Williams MT, Mellott C, Douglas CW. Plasma cortisol levels of dogs at a county animal shelter. Physiol Behav 1997;62(3):485-90.

[20] Brain PF. Adaptive aspects of hormonal correlates of attack and defense in laboratory mice: a study in ethobiology. Prog Brain Res 1980;53:391-413.

[21] Brain PF, Nowel NW, Wouters A. Some relationships between arenal function and the effectiveness of a period of isolation in inducing intermale aggression in albino mice. Physiol Behav 1970;6:27-9.

[22] Sieber-Ruckstuhl NS, Boretti FS, Wenger M, Maser-Gluth C, Reusch CE. Cortisol, aldosterone, cortisol precursor, androgen and endogenous ACTH concentrations in dogs with pituitary-dependant hyperadrenocorticism treated with trilostane. Domest Anim Endocrinol 2006;31(1):63-75.

[23] Coover GD, Heybach JP, Lenz J, Miller JF. Corticosterone 'basal levels' and response to ether anesthesia in rats on a water deprivation regimen. Physiol Behav 1979;22:653-6.

[24] Davidson JM, Jones LE, Levine S. Feedback regulation of adrenocorticotropin secretion in 'basal' and 'stress' conditions: acute and chronic effects of intrahypothalamic corticoid implantation. Endocrinology 1969;82:655-63.

[25] Riley V, Fitzmaurice MA, Spackman DH. Psychoneuroimmunologic factors in neoplasia: studies in animals. In: Ader R, editor. Psychoneuroimmunology. New York: Academic Press; 1981. p. 31-102.

[26] Beerda B, Schilder MBH, Van Hooff JARAM, De Vries HW, Mol JA. Behavioural and hormonal indicators of enduring environmental stress in dogs. Anim Welf 2000;9:49-62.

[27] Schwizgebel D. Zusammenhänge zwischen dem verhalten des tierlehrers und dem verhalten des Deutschen Schäferhundes im Hinblick auf tiergerechte ausbildung. Aktuel Arb Artgemass Tierhalt 1982:138-48.

[28] Hubrecht RC, Serpell JA, Poole TB. Correlates of pen size and housing conditions on the behaviour of kennelled dogs. Appl Anim Behav Sci 1992;34:365-83.

[29] Mertens PA, Unshelm K. Effects of group and individual housing on the behavior of kennelled dogs in animal shelters. Anthrozoös 1996;IX:40-51.

[30] Dantzer R. Behavioral, physiological and functional aspects of stereotypied behavior: a review and a reinterpretation. J Anim Sci 1986;62:1776-86.

[31] Broom D, Johnson K. Stress and animal welfare. London, UK: Chapman and Hall; 1993. p. 139.

[32] Lefebvre D, Diederich C, Delcourt M, Giffroy JM. Quality of the relationship between handlers and their military dog influences welfare and efficiency of these dogs. Appl Anim Behav Sci 2007;104(1-2):49-60.

[33] Goddard ME, Beilharz RG. A multivariate analysis of the genetics of fearfulness in potential guide dogs. Behav Genet 1985;15(1):69-89.

[34] Hughes HC, Campbel SA. Effect of primary enclosure size and human contact. In: Mench JA, Krulisch L, editors. Canine research environment. Proceedings of a conference, 22 June 1989, Bethesda, MD, USA. Bethesda, MD: Scientists Center for Animal Welfare; 2007. p. 66-73. [From Hetts, S., Clark, J.D., Calpin, J.P., Arnold, C.E., Mateo, J.M. Influence of housing conditions on beagle behaviour. Appl. Anim. Behav. Sci. 1992, 34:137-155.].

[35] Wonnacott TH, Wonnacott RJ. Statistique (économie, gestion, sciences, medicine). 4th Edition. Paris: Economia; 1995. p. 920.

[36] SAS OnlineDoc ${ }^{\circledR} 9.1 .3$. Copyright (C) 2002-2005 by SAS Institute Inc. Cary, NC, USA. All Rights Reserved.

[37] Henry JP, Stephens PM. Stress, health and the social environment. A sociobiological approach to medicine. New York: Springer Verlag; 1977.

[38] Takahashi Y, Ebihara S, Nakamura Y, Takahashi K. A model of human sleep-related growth hormone secretion in dogs: effects of 3, 6 and 12 hours of forced wakefulness on plasma growth hormone, cortisol and sleep stages. Endocrinology 1981;109:262-72.

[39] Kemppainen RJ, Sartin JL. Evidence for episodic but not circadian activity in plasma concentrations of adrenocorticotrophin, cortisol and thyroxine in dogs. J Endocrinol 1984;103:219-26.

[40] Kolevská J, Bruncklík V, Svoboda M. Circadian rhythm of cortisol secretion in dogs of different daily activities. Acta Vet Brno 2003;72:599-605. 
[41] Garnier F, Benoit E, Virat M, Ochoa R, Delatour P. Adrenal cortisol response in clinically normal dogs before and after adaptation to a housing environment. Lab Anim 1990;24:40-3.

[42] Steiss JE, Schaffer C, Ahmad HA, Voith VL. Evaluation of plasma cortisol levels and behavior in dogs wearing bark control collars. Appl Anim Behav Sci 2007;106(1-3):96-106.

[43] Beerda B, Schilder MBH, Janssen NSCRM, Mol JA. The use of saliva cortisol, urinary cortisol, and catecholamine measurements for a noninvasive assessment of stress responses in dogs. Horm Behav 1996;30:272-9.

[44] Weinberg J, Wong R. Adrenocortical responsiveness to novelty in the hamster. Physiol Behav 1986;37:669-72.

[45] Huhman KL, Moore TO, Feris CF, Mougey EH, Meyerhoff JL. Acute and repeated exposure to social conflict in male golden hamsters: increases in POMC-peptides and cortisol and decreases in plasma testosterone. Physiol Behav 1991;25:206-16.

[46] Adams GJ, Johnson KG. Guard dogs: sleep, work and the behavioural responses to people and other stimuli. Appl Anim Behav Sci 1995;46:103-15.

[47] Solomon RL, Wynne LC. Traumatic avoidance learning: acquisition in normal dogs. Psychol Monogr (Gen Appl) 1953;67(4):1-19.

[48] Odberg FO. The influence of cage size and environmental enrichment on the development of stereotypies in bank voles (Clethrionomys glareolus). Behav Processes 1987;14:155-73.

[49] Mason GJ, Latham NR. Can't stop, won't stop: is stereotypy a reliable animal welfare indicator? Anim Welf 2004;13:S57-69.

[50] Bildsøe M, Heller KE, Jeppesen LL. Effect of immobility stress and food restriction on stereotypies in low and high stereotyping female ranch mink. Behav Processes 1991;29:179-89.

[51] Hansen SW, Jeppesen LL. Temperament, stereotypies and anticipatory behaviour as measures of welfare in mink. Appl Anim Behav Sci 2006;99(1-2):172-82.

[52] Mason G, Rushen J. Stereotypic animal behaviour: fundamentals and applications to welfare. Chapter 11: stereotypic behaviour in captive animals: fundamentals and implications for welfare and beyond. Second ed. Trowbridge, UK: Cromwell Press; 2006. p. 325-56.
[53] Corson SA. Pavlovian and operant conditioning techniques in the study of psychosocial and biological relationships. Soc Stress Dis 1971;1:7-21.

[54] Voith VL, Borchelt PL. Fears and phobias in companion animals. In: Voith VL, Borchelt PL, editors. Readings in companion animal behavior. Trenton NJ: Veterinary Learning Systems; 1996. p. 124-39.

[55] Deputte BL. Ethological study of yawning in primates: I. Quantitative analysis and study of causation in two species of old world monkeys (Cercocebus albigena and Macaca fascicularis). Ethology 1994;98:221-45.

[56] Hennessy MB, Williams MT, Miller DD, Douglas CW, Voith VL. Influence of male and female petters on plasma cortisol and behaviour: can human interaction reduce the stress of dogs in a public animal shelter? Appl Anim Behav Sci 1998;61:63-77.

[57] Voith VL, Mc Grave E, Marder AR. Yawning, «licking» and sleep behaviors in dogs in relationship to conflict, anxiety and fear. Paper presented at the annual meeting of the Animal Behavior Society, Williamsburg, MA; 1987.

[58] Schilder MBH, van der Borg JAM. Training dogs with help of the shock collar: short and long term behavioural effects. Appl Anim Behav Sci 2004;85:319-34.

[59] Vas J, Topál J, Péch E, Miklósi A. Measuring attention deficit and activity in dogs: a new application and validation of a human ADHD questionnaire. Appl Anim Behav Sci 2007;103(1-2):105-17.

[60] Head E, Callahan H, Cummings BJ, Cotman CW, Ruehl WW, Muggenberg BA, et al. Open field activity and human interaction as a function of age and breed in dogs. Physiol Behav 1997;62:963-71.

[61] Bain MJ, Hart BL, Cliff KD, Ruehl WW. Predicting behavioral changes associated with age-related cognitive impairment in dogs. J Am Vet Med Assoc 2001;218:1792-5.

[62] Neilson JC, Hart BL, Cliff KD, Ruehl WW. Prevalence of behavioral changes associated with age-related cognitive impairment in dogs. J Am Vet Med Assoc 2001;218:1787-91.

[63] Wells DL, Graham L, Hepper PG. The influence of length of time in a rescue shelter on the behaviour of kennelled dogs. Anim Welf 2002;11:317-25. 